\title{
DESMILITARIZAÇÃO DAS POLÍCIAS MILITARES BRASILEIRAS: 0 QUE SIGNIFICA
}

\section{ARTIGO ORIGINAL}

SAIBERT, Alexandre Peixoto ${ }^{1}$

SAIBERT, Alexandre Peixoto. Desmilitarização das polícias militares brasileiras: o que significa. Revista Científica Multidisciplinar Núcleo do Conhecimento. Ano 06, Ed. 07, Vol. 05, pp. 83-97. Julho de 2021. ISSN: 2448-0959, Link de acesso: https://www.nucleodoconhecimento.com.br/lei/policias-militares-brasileiras, DOI: 10.32749/nucleodoconhecimento.com.br/lei/policias-militares-brasileiras

\section{RESUMO}

Este artigo apresenta os resultados de uma pesquisa bibliográfica a respeito da desmilitarização das polícias militares e o que significa de fato essa desmilitarização. O objetivo foi analisar o que significa desmilitarizar as polícias militares brasileiras, explicando como se deu a criação do modelo atual de polícia militar, sintetizar as propostas de desmilitarização e compreender aspectos da cultura policial militar que podem ser afetados pela desmilitarização. Os procedimentos metodológicos concentram-se na revisão de literatura. Os resultados sinalizam que desmilitarizar não é simplesmente acabar com o vínculo das polícias militares com Exército, tornando-as instituições de natureza civil.

Palavras-chave: Desmilitarização, Cultura Policial Militar, Polícia Militar.

\section{INTRODUÇÃO}

Estudiosos e populares criticam a atuação dos órgãos policiais do sistema de segurança pública, principalmente as polícias militares, por agirem com truculências e desrespeito aos direitos humanos. Criticam também pelo crescimento da violência

\footnotetext{
${ }^{1}$ Especialização em Políticas e Gestão em Segurança Pública pela Estácio, Graduação em Sociologia pela UNIP.

Disponível em: https://www.nucleodoconhecimento.com.br/lei/policias-militares$\underline{\text { brasileiras }}$
} 
em todo o Brasil ao longo dos anos. Neste contexto, a desmilitarização das polícias militares é uma das opções de mudanças no sistema de segurança pública, que foi apresentada nos últimos anos.

Este tema é importante pois tramita no congresso nacional algumas propostas de emenda à Constituição Federal (PEC), a fim de realizar a desmilitarização das polícias militares brasileiras, deste modo, é necessário se aprofundar neste assunto para entender de fato o que significa desmilitarizar as polícias militares.

Para quem pertence a uma instituição policial militar, aparentemente, é uma temática simples. Provavelmente possui uma opinião formada a respeito do assunto, sendo a favor ou contra esta possível mudança. Para quem não pertence a esse meio pode ser difícil de entender a dimensão legal e cultural[2] dessa mudança, pois as instituições possuem hábitos herdados, construídos e ressignificados ao longo dos anos, que são cultivados até os dias de hoje e difíceis de serem percebidos por quem não pertence a esse meio.

Com os protestos realizados por parentes de policiais militares no Estado do Espírito Santos no mês de fevereiro de 2017, onde ocorreu a paralização do policiamento ostensivo realizado pela PM[3], foi possível perceber, através das redes sociais, alguns debates acerca da desmilitarização e divergências quanto ao que isto significa de fato. Apesar de vários pesquisadores terem se debruçado sobre esta temática, direta ou indiretamente, este assunto não foi completamente esgotado, devido a amplitude das mudanças decorrentes da possível aprovação das propostas que tramitam no congresso nacional. Então, após aprofundamento nos aspectos relativos a este assunto, será possível se aproximar da solução ou resolver o problema proposto, que é compreender o que significa desmilitarizar as polícias militares.

Temos como objetivo geral, analisar o que significa desmilitarizar as polícias militares brasileiras. Os objetivos específicos são, explicar como se deu a criação das polícias militares; sintetizar as propostas de desmilitarização das polícias 
militares brasileiras; e, compreender aspectos da cultura policial militar que podem ser afetados pela desmilitarização.

A metodologia tem abordagem qualitativa, de caráter explicativo, feito através de levantamento bibliográfico, para entendimento e explicação das questões relacionadas às propostas de desmilitarização e a cultura policial militar. Este levantamento foi realizado através da plataforma de periódicos da CAPES e "google acadêmico". As propostas de emenda à constituição foram consultadas através dos sites oficiais da Câmara dos Deputados e do Senado Federal.

Primeiramente faremos uma síntese do percurso histórico das polícias militares para esclarecer como se chegou no atual modelo de segurança pública no âmbito estadual, onde elas estão inseridas. Posteriormente realizaremos a síntese das propostas de emenda à constituição que tratam de modificações do sistema de segurança pública brasileira, focando na transformação das polícias militares em instituições de natureza civil, já que se trata da principal modificação no sistema de segurança pública. E finalmente, para ficar claro a dimensão dessa mudança, no comportamento, no treinamento, na formação dos policiais e consequentemente no trato com a população durante o patrulhamento ostensivo, compreenderemos como é a dinâmica da cultura cultivada no meio policial militar ao longo dos anos.

\section{POLÍCIA MILITARIZADA}

O processo de formação das polícias militares é longo, com seu embrião nascido no período do império, com a chegada da família real ao Brasil em 1808. Utilizando experiências testadas em Portugal, o príncipe criou a Intendência Geral de Polícia, órgão com poderes judiciais, porém administrativo, não possuía pessoal para fiscalizar e impor o cumprimento de suas decisões. Logo, foi criada a Divisão Militar da Guarda Real para cumprir esse papel. As duas instituições são os embriões das Polícias Civis e Polícias Militares (BRETAS, 1998). Segundo Muniz (2001), a Guarda atuava em repressão ao contrabando, para capturar e prender escravos, desordeiros e criminosos e era organizada aos moldes militares. 
O curso de divisão das polícias em militar e civil, fardada e velada, foi impulsionado em 1866, quando entrou em vigor o Decreto n 3.598, de 27 de janeiro de 1866[4], que instituiu esta divisão. Sendo intensificado ainda mais quando a "Missão Militar Francesa" chegou ao Estado de São Paulo, contratada pelo governo do estado, para formar e moldar a polícia militar paulista (SILVEIRA, 2013).

Entretanto, este modelo instituído por um Decreto, era frágil, pois o decreto poderia ser modificado com facilidade, portanto este sistema de segurança não possuía a estabilidade que existe atualmente. $O$ sistema de segurança pública passou a ter uma estabilidade maior a partir do momento em que foi definido através da Constituição Federal.

Esse modelo brasileiro de polícia militar, foi definido constitucionalmente no governo militar, através da Constituição Federal de 1946, no Art. 183, onde era definido que "as polícias militares, instituídas para a segurança interna e a manutenção da ordem nos Estados, nos Territórios e no Distrito Federal, são consideradas, como forças auxiliares, reservas do Exército." (BALEEIRO e SOBRINHO, 2012, p. 91). E este sistema permaneceu nas Constituições Federais de 1967, 1969 e na de 1988, Art. 144 ,

$\S 5^{\circ}$ Às polícias militares cabem a polícia ostensiva e a preservação da ordem pública; aos corpos de bombeiros militares, além das atribuições definidas em lei, incumbe a execução de atividades de defesa civil. $\S 6^{\circ}$ As polícias militares e corpos de bombeiros militares, forças auxiliares e reserva do Exército, subordinam-se, juntamente com as polícias civis, aos Governadores dos Estados, do Distrito Federal e dos Territórios, cujo texto constitucional permaneceu semelhante ao de 1969.

Durante o processo de redemocratização no Brasil, na passagem da década de 80 para 90, várias modificações ocorreram no texto da nova constituição que surgira, porém, o capítulo referente à segurança pública, no que tange ao sistema de polícia militarizada, permaneceu praticamente intacto, neste sentido, segundo Silva e Gurgel (2016) o processo democrático de construção da Constituição Federal de 1988 não alcançou as instituições de segurança pública completamente. 


\section{PROPOSTAS DE EMENDA À CONSTITUIÇÃO}

As propostas de emenda à constituição (PEC), que serão abordadas neste momento, tramitam no Congresso Nacional, tanto na Câmara dos Deputados quanto no Senado Federal. Em ordem cronológica, por ano, são: PEC 430/2009, PEC 432/2009, PEC / 102/ 2011, PEC 51/2013 e PEC 423/2014. Tramitando na Câmara dos Deputados estão as PEC's 432/2009 e 423/2014 anexas à 430/2009, ou seja, estão caminhando justas, e no Senado Federal as PEC's 102/2011 e 51/2013.

\subsection{PEC 430/2009}

Nesta proposta a Constituição Federal de 1988 teria a seguinte redação:

Art. $144[\ldots] \S 4$ 4… A Polícia dos Estados e do Distrito Federal e Territórios, instituída por lei como órgão único em cada ente federativo, permanente, essencial à Justiça, de atividade integrada de prevenção e repressão à infração penal, de natureza civil[5], organizada com base na hierarquia e disciplina e estruturada em carreiras, destina-se, privativamente, ressalvada a competência da União, à: I - preservação da ordem pública; II - exercer a atividade de polícia ostensiva e preventiva; III - exercer a atividade de investigação criminal e de polícia judiciária, ressalvada a competência da União e as exceções previstas em lei. [...] (CÂMARA, 2009, p. 2).

As Polícias dos Estados e do Distrito Federal seriam inicialmente formadas pelas respectivas polícias Civis e Militares.

Segundo o autor, as mudanças são necessárias para a criação de uma polícia nova, que trate o cidadão adequadamente. Para evitar também, a duplicidade de estruturas físicas, evitar que as polícias militares avancem nas atribuições das polícias civis e vice-versa e eliminar a falta de integração entre essas, devido a existência de gestores distintos. 


\subsection{PEC 432/2009}

Esta proposta é semelhante à anterior e através dela a Constituição Federal terá a seguinte redação:

Art. 144 [...] IV - polícia e corpo de bombeiros dos Estados; V polícia e corpo de bombeiros do Distrito Federal e Territórios, mantidos pela União; § 4‥ A polícia dos Estados e do Distrito Federal e Territórios, de natureza civil[6], instituída por lei como órgão permanente e único em cada ente federativo, essencial à Justiça, subordinada ao respectivo Governador, de atividade integrada de prevenção e repressão à infração penal, dirigida por autoridade policial, organizada com base na hierarquia e disciplina e estruturada em carreiras, ressalvadas a competência da União, destina-se: I - à preservação da ordem pública; II - à polícia ostensiva e preventiva; e III - ao exercício privativo da investigação criminal e da atividade de polícia judiciária, sob a presidência da autoridade policial. [...] (CÂMARA, 2009, p. 2).

Segundo os autores, as mudanças são necessárias pois na criação e aprovação da Constituição os legisladores tiveram a oportunidade de modificar o sistema de segurança pública vigente na época e não o fizeram; e este modelo não se encaixa no atual sistema democrático. Citam ainda que tais mudanças são necessárias para que se tenha uma polícia de ciclo completo[7], a fim de evitar a duplicidade de estruturas físicas, evitar que as polícias militares avancem nas atribuições das polícias civis e vice-versa, pois uma necessita do trabalho da outra para combater a criminalidade e também eliminar a falta de integração entre essas.

\subsection{PEC 102/2011}

Através desta proposta a Constituição Federal terá a seguinte redação:

Art. 144[...] § 10. É facultado à União, no Distrito Federal e Territórios, e aos estados a adoção de polícia única, no seu respectivo âmbito, cujas atribuições congregam as funções de polícia judiciária, a apuração de infrações penais, de polícia ostensiva, administrativa e a preservação da ordem pública. [...] (SENADO, 2011, p. 1). 
Segundo o autor as modificações são necessárias devido tanto ao crescimento da criminalidade, verificado desde a década de 90 , que desvela a ineficiência dos órgãos de segurança pública no combate a essa criminalidade, quanto a pressão da sociedade, principalmente, em momentos de escândalos envolvendo policiais, no tocante a violação de direitos.

A criação de polícias estaduais civis está prevista nesta proposta, entretanto esta mudança será opcional, ou seja, ficará a critério dos governos dos estados permanecer com sistema de segurança atual ou unificar as polícias civis e militares em um órgão único.

\subsection{PEC 51/2013}

Através desta proposta a parte da Constituição Federal que trata da segurança pública iniciará no Art. 143-A.

Art. 143-A. A segurança pública, dever do Estado, direito e responsabilidade de todos, é exercida para a preservação da ordem pública democrática e para a garantia dos direitos dos cidadãos, inclusive a incolumidade das pessoas e do patrimônio, observados os seguintes princípios: [...] Parágrafo único. A fim de prover segurança pública, o Estado deverá organizar polícias, órgãos de natureza civil, cuja função é garantir os direitos dos cidadãos, e que poderão recorrer ao uso comedido da força, segundo a proporcionalidade e a razoabilidade, devendo atuar ostensiva e preventivamente, investigando e realizando a persecução criminal (SENADO, 2013, p. 2, grifo nosso).

Neste artigo fica claro a intenção de transformar as polícias militares em instituições de natureza civil, semelhante aos outros órgãos de segurança pública, e complementa com o Art. 144-A, onde fica determinado que, no âmbito do Estados, Distrito Federal e Municípios, todas as polícias deverão ordenar suas ações em ciclo completo.

Em comparação com as propostas anteriores a grande diferença é a possibilidade de criação de polícias municipais de ciclo completo, que atuarão de maneira 
complementar às polícias estaduais, conforme as responsabilidades acordadas com cada estado.

Segundo o autor, tais mudança são necessárias pois o sistema de segurança pública brasileiro ficou obsoleto com o decorrer dos anos. A rigidez das instituições militares é excessiva para a autonomia do policial, as atividades de policiamento ostensivo e investigação criminal devem pertencer a mesma instituição, e ainda, inserção dos municípios no sistema é concretizada de forma objetiva, tornando-os também, responsáveis diretos pela segurança pública.

\subsection{PEC 423/2014}

Através dessa proposta a constituição terá a seguinte redação:

Art. $144 \quad[\ldots] \quad \S \quad 8^{\circ}$ Os municípios poderão constituir guardas municipais, organizadas em carreira, nos termos da lei, destinadas á proteção de seus bens, serviços e instalações municipais, e nos termos da lei complementar exercer ações de patrulhamento ostensivo, sem prejuízo da atuação dos demais órgãos públicos na esfera de suas competências; [...] § 10. Além das competências específicas, os órgãos e instituições policiais previstos nos incisos do caput deste artigo, realizarão a polícia única, consistente no ciclo completo de ação policial na persecução penal[8], exercendo cumulativamente as polícias administrativa, ostensiva, preventiva, investigativa, judiciária e de inteligência policial, sendo as atividades investigativas, na ação penal pública, independente da sua forma de instrumentalização, realizada em coordenação com o Ministério Público (CÂMARA, 2014, p. 2).

Segundo o autor, essa proposta está alinhada com princípios e diretrizes votados na 1ª CONSEG - Conferência Nacional de Segurança Pública em 2009 e são mudança necessárias para a modernização do sistema de segurança pública. De acordo com o mesmo, este modelo de patrulhamento, no qual se tem viaturas equipadas com rádios, foi iniciado na década de 70, aparentemente parecia ser ideal, mas ao longo dos anos se tornou insuficiente às demandas, facilitando o aumento dos crimes em quantidade e variedade. 
Na nova redação proposta para o artigo 144 da constituição ele não deixa claro que a polícia única de ciclo completo será de natureza civil. Entretanto ele critica a centralização excessiva existente no modelo atual, característica das instituições militares, logo, é possível perceber a intensão do autor para que sejam de natureza civil.

\section{CULTURA POLICIAL MILITAR}

Com a manutenção desse modelo de segurança pública, as policias militares permaneceram vinculadas ao Exército Brasileiro como forças auxiliares, consequentemente a estrutura hierárquica, o treinamento e a formação dos policiais permaneceram semelhantes ás daquele, voltada principalmente para o combate ao inimigo, como citado na PEC 51, "A função de policiar as ruas é exclusiva de uma estrutura militarizada, força de reserva do Exército - a Polícia Militar -, formada, treinada e organizada para combater o inimigo, e não para proteger o cidadão.". Silva e Gurgel (2016) concordam que a manutenção do vínculo das polícias militares com as Forças Armadas interfere diretamente na educação, formação, treinamento e no trato com o cliente final do serviço de segurança pública, reflexos da rigidez cultivada no meio militar através da hierárquica e disciplina incontestáveis. A ligação e "isonomia" organizacional existente entre as instituições é bem exemplificada através do Decreto-Lei no 667, de 2 de julho de 1969 e do Decreto no 88.777, de 30 de setembro de 1983, nos quais, em linhas gerais, o primeiro reorganiza as Polícias Militares e os Corpos de Bombeiros Militares dos Estados, dos Territórios e do Distrito Federal e o segundo aprova o regulamento para as policias militares e corpos de bombeiros militares (R-200), que são as normas gerais a serem seguidas pelas instituições militares estaduais.

Dentro das atribuições do Exército a missão principal é a garantia e proteção da soberania nacional, sendo necessário estar preparado para guerra. Esta condição exige que essa instituição tenha capacidade de emprego de grandes contingentes e material com rapidez. Devido a esta finalidade é necessário e aceitável a centralização e rigidez da estrutura hierárquica (SOARES, 2015). As polícias 
militares compõem o rol de instituições de segurança pública, voltadas para a preservação e garantia de direitos individuais e coletivos previstos na legislação brasileira vigente, diferente do propósito do exército, do qual é copiada a estrutura hierárquica e disciplinar pelas polícias militares. "Destarte, os constituintes deixaram de observar a separação que deve necessariamente existir entre as instituições que são responsáveis pelas atividades voltadas à defesa nacional e à proteção da segurança interna em uma ordem democrática" (SILVA e GURGEL, 2016, p. 154).

O treinamento no Exército inicia com o ingresso por alistamento obrigatório ou por concurso público. Tendo em vista as atribuições da instituição, a formação possui elevado grau de esforço físico, estresse psicológico e submissão indiscutível ao superior hierárquico, a fim de forjar quem desempenhará as missões atribuídas à instituição.

A formação e treinamento nas polícias militares possuem características semelhantes, com trotes de rito de ingresso, ritos de nivelamento e ritos de formatura (ALBUQUERQUE e MACHADO, 2001), em alguns casos, incluindo também atividades em meio a mata, que podem ser verificadas

como um momento de grande ambivalência, uma vez que, ainda que se trate de apenas uma atividade extracurricular, assume proporções na transmissão da identidade profissional maiores que o conjunto de disciplinas que compõem 0 amplo quadro curricular. Nessa perspectiva, a JIM[9] teria a propriedade de inverter e debilitar os conteúdos do novo currículo oficial [...]. (ALBUQUERQUE e MACHADO, 2001, p. 215).

Através dessa combinação controversa de ensinamentos que se busca de um lado formar o profissional policial e do outro a mística militar, se faz do corpo um condutor de intensas atividades físicas para que se alcance o prêmio de ser policial militar (FRANÇA e GOMES, 2015).

No curso de formação de oficiais da PM baiana os alunos chegaram a se questionar sobre a aplicabilidade das atividades a que estavam sendo submetidos no dia a dia do policiamento da PM, pois essas atividades colidiam diretamente com a grade 
curricular proposta (FRANÇA e GOMES, 2015). Para Silveira (2013), esse tipo de treinamento voltado diretamente ao enfrentamento, ao combate, evidentemente vai estabelecer uma padrão de atuação semelhante, durante o patrulhamento ostensivo realizado pelas policias militares.

Este padrão de formação fica mais intenso de acordo com o curso que está sendo ofertado. Nos cursos de formação inicial são menos intensos, entretanto pode causar grande impacto pois é o primeiro curso que o policial realiza. Os cursos mais operacionais, ou voltados para atividades específicas, por exemplo, para os batalhões de força tática, choque, cavalaria e operações especiais, estes padrões de formação são mais intensos.

Segundo Silva e Gurgel (2016) a desmilitarização das polícias militares não significa manter uma polícia desarmada, e sim, desvinculá-las do Exército Brasileiro, transformando-as em instituições de natureza civil, através da unificação das polícias civis e militares dos respectivos entes federados, e possibilitando o ganho de direitos trabalhistas a esses militares. Silveira (2013) concorda, dizendo que desmilitarizar não é igual a desarmar de desequipar as polícias, e sim uma forma de aumentar a capacidade de as polícias cumprirem suas funções constitucionais.

Medeiros (2005) complementa dizendo que, segundo Costa e Medeiros (2003) a desmilitarização pode ser realizada em seis dimensões:

* Organização: A polícia absorve modelos organizacionais, símbolos e linguagem utilizados pelas forças armadas. * Treinamento: A polícia adota armas, treinamento e códigos disciplinares militares. * Emprego: Táticas e estratégias militares são incorporadas à atividade policial. Um bom exemplo são as unidades paramilitares de polícia. * Controle: A estratégia policial é definida pelas forças armadas. Se as forças armadas não dirigem a ação policial, podem controlar alguns de seus aspectos, como a compra de armamento e a distribuição geográfica do policiamento. * Inteligência: Atividades de inteligência são controladas pelas forças armadas ou de algum modo influenciadas pelo processo decisório militar. * Justiça: A polícia está inteira ou parcialmente sujeita à jurisdição de tribunais militares (MEDEIROS, 2005, p. 246). 
Todos estão alinhados com as propostas de emenda à constituição, em que, desmilitarizar envolve mudança de postura, modificação na estrutura organizacional, formação do policial militar e na forma de emprego das polícias militares.

\section{CONCLUSÃO}

As polícias militares possuem suas raízes no período do império, com a criação da Divisão Militar da Guarda Real, instituição de natureza militar responsável por executar as decisões da Intendência Geral de Polícia, o embrião das polícias civis. O modelo atual foi definido 138 anos após a criação da Divisão Militar da Guarda Real, através da promulgação da Constituição Federal de 1946, as polícias militares, definidas como forças auxiliares do exército, ficaram responsáveis pela segurança interna e manutenção da ordem no âmbito dos governos estaduais.

O modelo de polícia militar instituído neste período é o modelo que vigora até os dias atuais. Apesar de ter havido modificações significativas em outros serviços públicos essenciais, na Constituição Federal de 1988, o modelo de segurança pública, na esfera estadual, permaneceu praticamente intacto.

As propostas de emenda à constituição que tratam de modificações no sistema de segurança pública, possuem como a mudança mais significativa a desmilitarização das polícias militares e são propostas bem semelhantes, que divergem apenas em poucos detalhes, como a possibilidade de implantação de polícias municipais ou a autonomia dos estados em criar uma polícia estadual única ou permanecer com duas instituições.

Em sua maioria propõem a criação de uma polícia estadual única, de natureza civil, organizada em ciclo completo, de modo que a mesma instituição policial realize o policiamento ostensivo e a investigação criminal, mantendo o órgão policial atuando em todo o processo; sendo inicialmente composto pelos membros das polícias civis e militares. 
Essas mudanças são necessárias para a melhoria da qualidade dos serviços e integração das polícias, pois, a atuação de uma é essencial para o serviço da outra; para a redução de custos com a duplicidade de estruturas físicas, diminuição da competitividade e atritos existentes entre policiais militares e civis; e, a rigidez das polícias militares é um aspecto negativo para a autonomia que o policial necessita durante a execução do serviço.

As polícias militares possuem uma carga cultural herdada do Exército cultivada ao longo dos anos. Essa cultura influencia diretamente em aspectos internos das instituições, como organização, treinamento, emprego e controle. São organizadas semelhante a estrutura organizacional do Exército, com postos e graduações semelhante e os mesmos rituais de formatura militar; o treinamento, consequentemente, também assume contornos semelhantes, com instruções voltadas pincipalmente para o enfrentamento e combate, com grande carga de esforço físico, a fim de forjar o policial militar. O emprego e controle são resultados da rigidez de uma instituição militar, com grande centralização e pouca autonomia para os policiais de baixa patente.

Percebemos que a desmilitarização é algo abrangente e complexo, que não é somente a modificação da constituição objetivando acabar com o vínculo existente entre as Polícias Militares e o Exército e transformando-as em instituições de natureza civil. É tornar em instituições de natureza civil através de modificações da legislação, na estrutura organizacional, na reformulação e ressignificação do treinamento, emprego e da sistemática de controle.

Diante de todo esse contexto citado é possível perceber também que, ao serem aprovadas tais modificações, os resultados não serão imediatos. O processo de mudança cultural será longo, pois a cultura existente é resultado de um longo processo histórico.

\section{REFERÊNCIAS}


ALBUQUERQUE, C. L. D.; MACHADO, E. P. Sob o Signo de Marte: modernização, ensino e ritos da instituição policial militar. Sociologias, Porto Alegre, n. 5, p. 214237, jan/jun 2001. ISSN 1807-0337. Disponivel em: <http://dx.doi.org/10.1590/S1517-45222001000100010>. Acesso em: 13 Fevereiro 2017.

AULETE, C. Dicionário Caldas Aulete da língua portuguesa: edição de bolso. Rio de Janeiro: Lexikon Editora Digital, 2007.

BALEEIRO, A.; SOBRINHO, B. L. CONSTITUIÇÕES BRASILEIRAS. 3a . ed. Brasília: Senado Federal, Subsecretaria de Edições Técnicas, v. V, 2012. 121 p.

BRASIL. CONSTITUIÇÃO DA REPÚBLICA FEDERATIVA DO BRASIL DE 1967. Palácio do Planalto, 24 jan. 1967. Disponivel em: <http://www.planalto.gov.br/ccivil_03/Constituicao/Constituicao67.htm>. Acesso em: 12 set. 2016.

CONSTITUIÇÃO DA REPÚBLICA FEDERATIVA DO BRASIL DE 1988. Palácio do Planalto, 05 out. 1988. Disponivel em: <http://www.planalto.gov.br/ccivil_03/Constituicao/Constituicao.htm>.

BRETAS, M. L. A polícia carioca no império. Revista Estudos Históricos, Rio de Janeiro, v. 12 , n. 22, p. 219-235, 1998. Disponivel em: <http://bibliotecadigital.fgv.br/ojs/index.php/reh/article/view/2075/1214>. Acesso em: 16 fevereiro 2017.

CÂMARA. Proposta de emenda à constituição n. 430, Brasília, 05 nov. 2009. Disponivel em: <http://www.camara.gov.br/proposicoesWeb/fichadetramitacao $?$ idProposicao=45850 0>. Acesso em: 12 set. 2016.

. Proposta de emenda à constituição n. 432, Brasília, 11 nov. 2009. Disponivel em: 
$<$ http://www.camara.gov.br/proposicoesWeb/fichadetramitacao?idProposicao=45929 4>. Acesso em: 15 jan. 2017.

. Proposta de emenda à constituição n. 423, Brasília, 06 ago. 2014. Disponivel em:

<http://www.camara.gov.br/proposicoesWeb/fichadetramitacao?idProposicao=62152 1>. Acesso em: 12 set. 2016.

CAVALCANTI, T. B.; BRITO, L. N.; BALEEIRO, A. CONSTITUIÇÕES BRASILEIRAS. 3a. ed. Brasília: Senado Federal, Subsecretaria de Edições Técnicas, v. VI, 2012. 206 p.

FRANÇA, F. G.; GOMES, J. L. D. F. "Se não aguentar, corra!": um estudo sobre a pedagogia do sofrimento em um curso policial militar. Revista Brasileira de Segurança Pública, São Paulo, v. 9, n. 2, p. 142-159, ago/set 2015. Disponivel em: <http://revista.forumseguranca.org.br/index.php/rbsp/article/viewFile/506/213>. Acesso em: 13 Fevereiro 2017.

MEDEIROS, M. A. A desmilitarização das polícias e a legislação ordinária. Revista de informação legislativa, Brasília, v. 42, n. 165, p. 239-253, jan./mar. 2005. Disponivel em: <http://www2.senado.leg.br/bdsf/handle/id/384>. Acesso em: 19 Março 2017.

MILANI, C. R. S. O princípio da participação social na gestão de políticas públicas locais: uma análise de experiências latino-americanas e européias. Revista de Administrção Pública, p. 551-559, 2008.

MIRANDA, J. D. C. B. D. POLICIAMENTO COMUNITÁRIO E DESMILITARIZAÇÃO: existe alguma correlação? Resvista do Laboratório de Estudos da Violência da UNESP/Marília, n. 12, p. 38-58, 2013. Disponivel em: <http://www2.marilia.unesp.br/revistas/index.php/levs/article/view/3475>. Acesso em: 12 set. 2016 . 
MUNIZ, J. A crise de identidade das polícias militares brasileiras: dilemas e paradoxos da formação educacional. Security and Defense Studies Review, $\begin{array}{lllll}\text { Colúmbia, } & \text { v. } & 1 & 2001 & \text { Disponivel }\end{array}$ <http://s3.amazonaws.com/academia.edu.documents/46105655/Crise_de_Identidad e_da_PM.pdf?AWSAccessKeyld=AKIAIWOWYYGZ2Y53UL3A\&Expires=148722162 2\&Signature=qm8mtU7pvVLj97CNivmTvQYikyY\%3D\&response-contentdisposition=inline\%3B\%20filename\%3DA_Crise_de_Identidade>. Acesso em: 16 fevereiro 2017.

RIBEIRO, P. J.; FERRAZ, T. C. (. ). SEGURANÇA PÚBLICA: temas e perspectivas. Rio de Janeiro: Garamond, 2012.

SENADO. Proposta de emenda à constituição n. 102, Brasília, 20 out. 2011. Disponivel em: <http://www25.senado.leg.br/web/atividade/materias//materia/102919>. Acesso em: 12 set. 2016.

Proposta de emenda à constituição n. 51, Brasília, p. 16, 25 set. 2013. Disponivel em: <https://www25.senado.leg.br/web/atividade/materias//materia/114516>. Acesso em: 12 set. 2016.

SILVA, G. G. E.; GURGEL, Y. M. P. A polícia na Constituição Federal de 1988: apontamentos sobre a manutenção de um órgão militarizado de policiamento e a sua incompatibilidade com a ordem democrática vigente no Brasil. Revista Brasileira de Segurança Pública, São Paulo, v. 10, n. 1, p. 142-158, 2016.

SILVA, J. D. Militarismo. In: SANSONE, L.; FURTADO, C. A. Dicionário crítico das ciências sociais dos países de fala oficial portuguesa. Salvador: EDUFBA, 2014. p. 494. Disponivel em: <http://repositorio.ufba.br/ri/handle/ri/14647>. Acesso em: 14 Fevereiro 2017.

SILVEIRA, F. L. D. S. REFLEXÕES SOBRE A DESMILITARIZAÇÃO E UNIFICAÇÃO DAS POLÍCIAS BRASILEIRAS. Congresso Internacional de Ciências Criminais, p. 15, 2013. Disponivel em: 
<http://ebooks.pucrs.br/edipucrs/anais/cienciascriminais/IV/34.pdf>. Acesso em: 12 set. 2016.

SOARES, L. Entrevista concedida a Vitor Suarez. Rio de Janeiro. 14 abr. 2015. Disponível em: <https://www.youtube.com/watch?v=gLiYyqap-sc\&t=1207s>. Acesso em: 13 fev. 2017.

\section{APÊNDICE - REFERÊNCIAS DE NOTA DE RODAPÉ}

2. "[...] O conjunto de conhecimentos de um indivíduo. [...] A soma de conhecimentos que os homens acumulam e transmitem através de gerações [...]. Costumes de um grupo social" (AULETE, 2007).

3. Polícia Militar.

4. Disponível em http://www2.camara.leg.br/legin/fed/decret/1824-1899/decreto3598-27-janeiro-1866-554213-publicacaooriginal-72693-pe.html. Acessado em 15 de fevereiro de 2017.

5. Grifo nosso.

6. Grifo nosso.

7. Polícia de ciclo completo é aquela que realiza o policiamento ostensivo, uniformizado, para a prevenção do crime, e investigação, para a repressão do crime, que atualmente são funções desempenhadas separadamente pelas Polícias Militares e Civis no âmbito dos Estados.

8. Persecução penal é o caminho que a administração pública percorre após o cometimento de um crime. A primeira fase é de investigação e a segunda é a ação penal, iniciada após a denúncia do Ministério Público.

9. Jornada de Instrução Militar. 
Enviado: Maio, 2021.

Aprovado: Julho, 2021. 